\title{
Goal-Setting and Shaping of Bilingualism among Junior High School Learners
}

\author{
Anna Buzek-Kolarczyk, Krzysztof Polok \\ University of Bielsko-Biala, Bielsko-Biala, Poland \\ Email: sworntran@interia.pl
}

How to cite this paper: Buzek-Kolarczyk, A. and Polok, K. (2020) Goal-Setting and Shaping of Bilingualism among Junior High School Learners. Open Access Library Journal, 7: e6021.

https://doi.org/10.4236/oalib.1106021

Received: December 23, 2019

Accepted: January 11, 2020

Published: January 14, 2020

Copyright $\odot 2020$ by author(s) and Open Access Library Inc.

This work is licensed under the Creative Commons Attribution International License (CC BY 4.0).

http://creativecommons.org/licenses/by/4.0/

(c) (i) Open Access

\begin{abstract}
The paper discusses the ways junior high school learners may be helped to become bilingual speakers with the help of appropriately applied goal-setting technique. The research done among junior high school teachers who used the goals setting technique revealed positive correlation between the application of goal-setting in the junior high school classes and the FL results of the learners attending such lessons. The result of these learners, when contrasted with the results of their peers attending the classes taught by the teachers who did not use goal-setting showed that the first group of learners was much better during the obligatory mock exam all junior school learners have to take at the end of their school education.
\end{abstract}

\section{Subject Areas}

Education

\section{Keywords}

FLE Education, Goal-Setting, SMART Model, Bilingualism,

Classroom Bilingualism

\section{Introduction}

Today we are living in a world where knowing two languages has become something obvious. Children are learning English since first grade, or even earlier in the kindergarten. In the contemporary world they are surrendered by the English language, not only at school, but also on the internet, playing games, watching movies, etc. They are slowly becoming bilingual people. The teachers' role is to facilitate that process and move forward with the development.

Nowadays more and more teachers are wondering how to help their students which the problem of lack of motivation. It is one of the several reasons which 
handicap learning a second language, thus becoming a bilingual. It has become a common obstacle, especially among young learners who are permanently distracted by such factors as television, internet, phones, and other media. There are several techniques which aim at increasing and maintaining the motivation, in this article we would like to discuss the goal-setting method.

\section{Literature Review}

Our research was created on the basis of four researches and the theoretical background. In order to analyse the field of study, we examined surveys which relates to the issue of goal setting, and its impact on learning foreign language. Each survey revealed the positive consequences of goal setting on various area of learning foreign language, generally speaking, on the performance in English. Therefore, we come up with the idea to develop these studies and examine the topic form the different perspective. Before we present our research we would like to briefly describe the theory of our survey.

There are two basic terms which have to be explained before we discuss our research: bilingualism and goal-setting. Bilingualism has got many definitions; according to [1] the phenomenon of bilingualism occurs when a person is able to use two languages, not only in the same modality, but also when mixing them, an example might be writing Spanish and English Sign language.

Bloomfield (in: [2]) determined bilingual person very precisely as the one having "native like competence in both languages". Unfortunately, this definition refers only to the very limited amount of second language users.

According to [2] a bilingual person is every learner of a foreign language, because: “(...) any language learner is an incipient bilingual. Any bilingual is or was a language learner". We are of the opinion that this definition is the most broaden one and the term bilingualism in this work will refer to that definition because of several reasons. It does not set a ridged border between bilingualism and second language learning, as this border is almost impossible to be determined. Moreover, every language user is constantly learning, even when it come to the mother tongue, let alone getting to know a new language.

The second term that has to be explained is goal setting. The basic term-a goal, is clearly defined by [3] were we can read that it is "something that you hope to achieve". Goal-setting is a technique that relies on the study of [4], who examined the relationship between goal setting and performance, according to [1]. They claimed that a goal has an impact on final performance in four ways: supports persistence, facilitates choosing a direction in learning, evokes more effort form learners and supports strategy of development.

Other positive results of goal-setting were described by [5], he admitted that this techniques has influence on people in such aspects as: support commitment to the activity, increases motivation, increases persistence and support the willingness to learn new material.

There are several models or theories of a perfect goal-setting plan. One of the 
most popular is the SMART model, which might be adapted to several areas of life. According to [6], we may develop the acronym SMART in the following way:

S (specific) - an aim that we are hoping to achieve has to be precisely defined;

> $\mathbf{M}$ (measurable) - a person who sets a goal should be able to find out at what stage of achieving he or she is, it is also important to set not a general aim, but that one that is possible to be measured;

> A (attainable) - a person have to be able to complete the task, it cannot be too difficult, as it may discourage him or her;

$\mathbf{R}$ (relevant) - the goal has to be important for a person;

$\mathrm{T}$ (time-oriented) - when setting a goal we have to determine the time when is should be achieved, in order not to postponing it.

\section{Materials and Methods}

We decided to use quantitative method for this survey, due to various reasons. First of all, this type of research allows to present the results in figures and numbers, which is very objective and precise way of analysing research. Secondly, we had an opportunity to conduct a survey with a help of questionnaires, whereas the personal conversations with teachers would be impossible.

We prepared our survey on the basis of four surveys which examined the relationship between goal-setting and development of English. These surveys were conducted by [1] [7] [8] [9]. They examined mostly students, whereas we decided to survey the relationship between teachers' positive beliefs in goal-setting and their learners' achievements in English language. Thus, our research was principally based on the theory of goal-setting by [5], as well as the relationship between goal-setting and performance thoroughly examined by [1].

\subsection{Participants}

The research sample of our study consists of forty-four teachers of English, who teach in the eighth grade of Polish junior high schools. There were seven men and thirty-seven women in the group. The average age of the respondent was estimated at thirty-six years old.

We decided to carry out a survey on this specific group of teachers, as they are teaching children who were obliged to write the eighth graders exam. The test is reliable source of knowledge of how children are developed in the English language. The tests are obligatory in Poland and checked by independent commissions. The exam lasts ninety minutes and examined students in the area of listening and reading comprehension and writing skills. Moreover, it checks functions of language phrases and vocabulary—that means almost all language skills.

\subsection{Instrument}

For the purposes of our research we have created a questionnaire for teachers. It consists of metrics and six open and close questions. The first three questions 
ask about general information about the participants: age, sex, and job seniority. Question four consists of fourteen statements, the respondents were asked to mark how much they agree or disagree with each of them, on the five grade Likert Scale. The aim of this question was to know teachers' opinion on different aspects of goal-setting. The list of sentences is presented below:

1) "Goal setting" helps students to understand which learning strategies are the best for them;

2) Goal setting support persistence;

3) If children can autonomously set goals, more often they focus on the proper activities than on the one that does not have any sense;

4) The more difficult the goal is, the more motivated the student is;

5) Feedback has a positive impact on the development of second language among children;

6) Providing feedback motivates students;

7) It is more beneficial if a student independently sets goals than when a teacher does it for him or her;

8) Goal-setting supports development of autonomy;

9) Autonomy plays an important role in the process of learning;

10) Goal setting increases students' motivation;

11) Writing down a goal might have an impact on effectiveness of the goal;

12) Goal setting increases intrinsic motivation;

13) The ability to set appropriate goals can be developed;

14) Planning has a positive impact on the foreign language learning.

In the succeeding question, the teachers are asked to write features of a goal they reckon as motivating. The purpose of this part was to discover what kind of goals are the most successful, according to the teachers.

Then, in the next question we ask whether teachers practice or not the goal-setting technique. This question is followed by an additional explanatory question asking the teachers to describe how they practice this technique. This question was asked to shed some clarifying light on the usage of this technique. In the subsequent question those of the examined teachers who revealed they did not use the goal-setting technique were requested to provide the reasons explaining why they did not apply this technique. From these answers we hope we might draw conclusions concerning the weaknesses of this method of motivating the learners.

The penultimate question required the teachers to define the term goal-setting, in order to check whether our respondents knew the basic term. The purpose of this question was also to shed some light on the technique of goal-setting in the area of school learning.

In the last question the respondents were asked to write the average result from the mandatory mock exam of eight graders, obligatorily conducted each autumn in every Polish junior high school. The aim of this question was to compare the results obtained by the learners taught in the classes where goal-setting procedures were applied, and the result of the learners taught by the language teachers who did not practice this technique. 
The questionnaire was distributed in the groups of teachers on Facebook between April and May 2019.

\subsection{Variables}

Preparing our survey we found three pairs of variables that refer to our research topic (Table 1).

The first set of variables refers to the influence of goal setting techniques on learners' motivation. Goal setting is basically connected with planning learning, which might motivate students, as they see their progress and become informed how much they have to try to achieve a goal.

The second set of variables focuses on the impact of the goal setting approach on the development of learners' autonomy. An autonomous learner is a person who feels responsible for his/her learning process and can manage it on his/her own. This is also one of the most basic school aims-to create an autonomous person, able to handle different things and solve oncoming problems.

The last set of variables refers to the positive influence of student-focusing feedback and their development of foreign language proficiency. Giving feedback means instructing the students what is still needed to be done better. Following [6], such pieces of advice usually facilitate the process of learning foreign language.

\subsection{Hypothesis}

The aim of our research was to examine the relationship between shaping bilingualism, thus developing a foreign language, and the goal setting technique applied to junior high school learners. Therefore, our null hypothesis was formulated as follows: "Goal-setting has not got any impact on the development of bilingualism"; we hoped it should be rejected in the subsequent phases of the research.

\section{Results}

Beneath we present the results of our research. In the first segment of our questionnaire the examined teachers were asked to mark how much they agree (or disagree) with each of given sentences. We will briefly discuss the answers.

The first four questions referred to the idea offered by [1] and strengthened by the research done by [4], on the ways goal-setting influences one's language performance. Beneath we present the statements, together with the weighted averages of answers we obtained. The maximum score (5) meant that the researched

Table 1. Variables (own elaboration).

\begin{tabular}{ll}
\hline \multicolumn{1}{c}{ Independent } & \multicolumn{1}{c}{ Dependent } \\
\hline 1) Goal setting techniques & 1) Motivation \\
2) Goal setting techniques & 2) Development of autonomy \\
3) Feedback & 3) Development of English \\
\hline
\end{tabular}


teachers strongly agreed with the statement; the minimum score (1) referred to these answers the respondents strongly disagreed with:

Goal-setting supports persistence-3.43;

The more difficult the goal is, the more motivated the student is -2.25 ;

$>$ If children can autonomously set goals, more often do they focus on the proper activities than on the ones that do not have any sense-3.64;

> Goal-setting helps students to understand which learning strategies are the bet for them-3.14.

These results indicate that there is a positive relationship between goal-setting and the students' performance. The examined teachers agreed that this technique developed persistence, facilitated choosing proper learning strategy, and helped develop the ability to focus on appropriate activities. The only issue the teachers revealed their dubiousness concerned the dependence of the level of difficulty of goal setting on a student's motivation. It might be due to the fact that students in junior high school still need positive feedback, not only difficult requirements.

In order to examine the nature of the relationship between goal-setting techniques and motivation, establish the function performed by teachers in the process of learning the language, the respondents were given the following statement:

I personally believe that goal setting increases students' motivation.

The weighted average was estimated at 3.32. Such a result indicates that teachers believe that goal-setting has an impact on motivation as well as that this technique may be used as a one of the tools motivating language learners to more intensified work.

The following two statements focused on the issue of feedback. By giving these statements we wanted to find out the existence of the relationship between giving feedback, as a part of a goal-setting technique, on the one hand and the development of motivation and success in learning a foreign language, on the other. These statements are presented below, together with the estimated average answer of each of them:

Feedback has a positive impact on the development of second language among children-3.8;

Providing feedback motivates students-3.68.

The answers of the teachers indicated that providing students with feedback results in the growing motivation and the development in the area of learning a language. These facts are important for teachers, as they suggest language teachers should take pains to give feedback to language students, informing them what elements they should practice more. The notion of feedback in goal-setting technique is strongly connected with formative assessment, which should occur during the process of learning to let student apply proper learning strategies.

The next group of statements refers to the relations that exist between goalsetting and a learner's autonomy. We wanted to find out whether goal-setting 
techniques influence the development of feature of autonomy in a language learner. The weighted average is placed next to each statement asked by us.

It is more beneficial if a student independently sets goals than when a teacher does it for him or her-3.16;

> Goal-setting supports development of autonomy-3.48;

Autonomy plays an important role in the process of learning-3.66.

The results of these statements-each sentence achieved the weighted average larger than 3.0-indicate that the examined teachers agreed that goal-setting has an impact on the development of learner's autonomy. The answers of the teachers showed that by applying goal-setting techniques, a learner might develop their personal level of independence in FL learning, what remains one of the main school aims-to create a person who can discover new knowledge by himself/herself.

The next two statements, largely based on the results of the researches done by [1] and [4], were connected with the process of the learner's personal involvement in language learning; first, we asked whether goal-setting increases intrinsic motivation (the weighted average answer was 3.4 here). It means that the teachers believe such techniques affect learners' intrinsic motivation, as they come closer to the process of language learning, in this way feeling more responsible of their personal achievements. The second statement asked by us was:

Writing down a goal might have an impact on effectiveness of the goal;

It was also supported by the teachers, as the weighted average was estimated at 3.48. Consequently, the researched teachers believed that success in foreign language becomes more certain if both the teachers and the learners had put down their goals. Therefore, teachers should encourage students to keep an eye on the way they had described their learning targets, as it might bear positive consequences.

The next sentence the examined teachers were requested to answer was connected to the study made by [7]. The statement we asked looked as follows:

The ability to set appropriate goals can be developed.

It achieved one of the highest weighted averages-3.82. Consequently, it could be recognized as a form of evidence that appropriate setting of educational goals is a skill that can be developed in learners, so as to make everybody be able to learn and perfect one's knowledge all the time.

The final sentence the respondents were requested to provide their opinions was related to the general idea of planning (basically understood as goal-setting). The weighted average of sentence: Planning has a positive impact on foreign language learning, was estimated at 3.3. Therefore, it may be assumed that while practicing lesson planning in the presence of students, introducing various goal-setting techniques may result in the students' ultimate success in learning. Such "planning" activities might be accomplished in several ways: preparing an organized lesson, encouraging learners to set goals, giving them aims, supporting and giving directions. 
The following section of our questionnaire was created to find out what features a lesson goal ought to possess in order to be motivating for a learner. In order to find it out we have decided to make use of the SMART model of goal-setting offered by [8], which consisted of basically five features. Each of the features thoroughly discussed by [8], was also claimed by the examined teachers.

The word specific was used by almost half of the respondents (45\%). We also accepted answers which-in a way-were connected to that feature, like for example: peculiar, concrete, proper, appropriate or suitable, that were clearly defined or given in simple sentences.

The word measurable was mentioned by four respondents only.

The most often used feature related to goal-setting by the respondents was the word achievable (exactly $50 \%$ of the answers). There were also several phrases that referred to that feature, for example: adapted to the level of proficiency of given group, possible to be achieved by students, etc. Some of the examined teachers also used a word realistic, which may be recognized as sharing the meaning with the keyword, as both words refer to the situation when a learner is able to achieve a given goal.

The feature relevant was written by two of examined teachers only. Both of them referred to that feature, indicating that a goal has to be important for learners and recognized as interesting to them.

The last feature occurring in the SMART model is time-oriented. This word was again used by two teachers in the answers we received. We also noticed a couple of answers which stated that a motivating goal had to be short-termed.

Moreover, the examined teachers claimed that a perfect goal has to be:

Formulated by students;

Created with a help of different techniques;

Fitted to the learner's needs;

$>$ Offer a prize or some kid of benefit;

Base on learner's knowledge;

$>$ A lesson should not contain more than two goals;

$>$ Be reminded;

Supported by teachers;

Ambitious;

$>$ Not too difficult;

Positive.

Concluding, the aim of this question was to find out the most relevant features of a motivating goal. As a follow-up, we also wanted to learn whether the respondents recognized the usefulness of goal-setting in their everyday educational activity. Several teachers declared they felt they had benefited from the SMART model, or some aspects of it. Quite many of them indicated the role of learner autonomy in setting a goal, the level of difficulty when setting goals, thought of it as a stimulus for students, stressed the teachers' role in supporting the student's educational goals set by them individually. Most of them, however, indicated that the important issue in setting a goal (with the students, or for them) was 
that it should fit their students' needs and expectations.

Exactly $50 \%$ of the examined teachers admitted they use goal-setting. In the additional question we requested these teachers to explain how they practice goal-setting in their work. Up to $1 / 5$ of the respondents wrote in their answers that setting goals ought to refer to the learners' autonomy. They admitted that they did not leave students with the whole responsibility to plan their learning, but rather supported them, gave directions and controlled the process. A strikingly contrastive view was presented by one teacher, who admitted that he (or she) simply notified the learners about the goals of the lesson by putting them down on the blackboard.

Almost $1 / 3$ of the teachers claimed that they practice goal-setting by simple talking about the goals with the learners. Some of them prefer a conversation with the whole class about how to prepare to the exam, what way to choose to learn effectively, find out the students' expectations, learn about their strengths and/or weaknesses. One teacher described that he (or she) prefers to talk with students about their long-term goals individually.

Among other responses we may distinguish such steps like: signing a contract, teacher's reminders, planning lessons and competitions with students each month, defining goals on every lesson/each month/after each test, usage of check-lists.

To sum up, up to the $50 \%$ of the examined teachers practice goal setting by talking with their students, they let them define a goal autonomously and/or serve as a help, providing them with support or working out to strengthen their motivation. However, one cannot forget about the other $50 \%$ of the teachers who confessed they did not practice goal-setting. Naturally, we asked them to explain the reasons of this approach.

Quite many teachers admitted that they never thought about it. The other numerous group of teachers explained that they simply did not have time for such activities; this is due to the fact that as the curriculum is overloaded, any additional activities take time. There are also behavioural problems in the class, which also take much time. Some teachers claimed that they forgot about this technique and one person even admitted that this method appeared to be useless for him/her. Two teachers informed us that they did not spend a lot of time on goal-setting, they just choose an aim and inform students about it.

As we suspected there might have appeared obvious discrepancies in the understanding of the term goal-setting among the researched teachers in one of the questions we asked them to define the term "goal-setting". Although none of the respondents answered it incorrectly, some of them focused on different aspects of this technique. Most of the teachers described the term just with the usage of different words. All the teachers' answers are presented in Figure 1 below.

Some teachers underlined that it is a process or an obligatory set of rules used when formulating a goal. They noticed that this might be a process which lasts and consists of several steps. One person wrote approached goal-setting focusing 


\section{Teachers positive beliefs concerning goal setting and results of students}

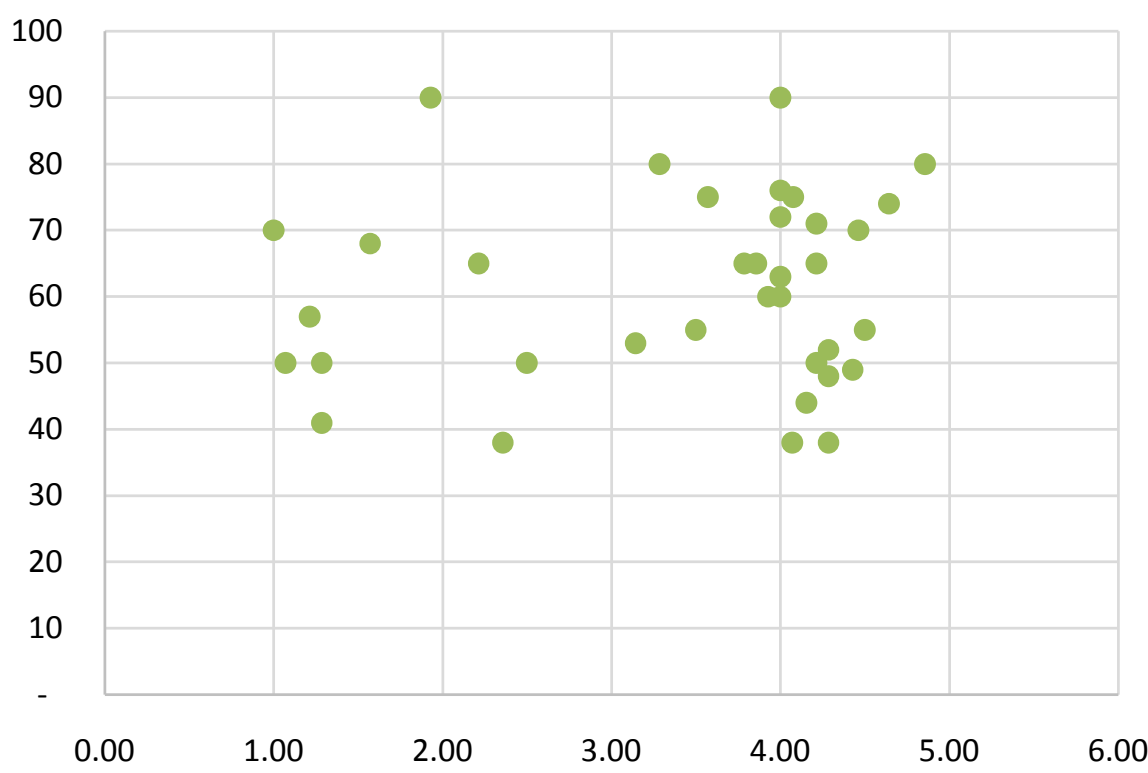

Figure 1. Teachers beliefs concerning goal-setting (own elaboration).

on the teacher only whose principal scope of responsibilities was to "set an aim of a lesson, that means what I would like to teach them".

Some of the examined teachers connected the term with separate features found in the SMART model, observing that it is, for example: "setting specific, educational goals", "setting achievable goals (...)", etc. There were also responses which focused on goal-setting as a tool responsible for increasing learners' motivation.

In the last question of the questionnaire the teachers were asked to write the average result of the mock exam of eighth graders that was conducted in autumn. This information was planned to function as a way useful to examine the relationship between a teacher's positive beliefs in goal-setting and the students' results. We counted the average of the answers from the segment of the questionnaire in which we counted the weighted averages of the statements, following the assumed pattern: the higher the result, the more a teacher supports goal-setting and the more s/he believes in its positive influence. Figure 1 above presents the relationship between the students' results (vertical axis), and teachers' beliefs (horizontal axis). The figure presents that quite a large amount of answers is located in the right top of the diagram. It indicates that these are the teachers who strongly support positive impact of goal setting, and whose students achieved high marks in the exam. We also analysed the results with a help of the Pearson correlation coefficient $r$, which was estimated at 0.12 . The achieved result means that there is a relationship between students' results and the teachers' assumptions. 


\section{Conclusion}

To conclude, the aim of this article was to present the results of our research, which was conducted to examine the existence of the relationship between goalsetting and the development of becoming linguistically proficient among junior high school learners. In it, so as to apply an objective research instrument, we focused on the influence of the teachers' beliefs in goal-setting and the results of the eighth graders mock exam, hoping that a positive correlation between the two segments should indicate the development of the learners' English in the objective way. The results of our study revealed that there is a positive relationship between these two factors. Consequently, as we rejected our null hypothesis ("goal-setting has not got any impact on the development of learners' bilingualism"), we found out that goal-setting is a useful tool in supporting children in their foreign language learning, as it positively influences the learners' motivation and helps in the development of their autonomy. This technique increases persistence and helps learners find a useful way of effective learning. Goal-setting awaits to be made use of at the moment one needs an impulse to help the language learners in two aspects at least; not only does it help them become positively motivated towards their linguistic tasks, but also permits them to change their attitude towards school (and after-school) education in general.

\section{Conflicts of Interest}

The authors declare no conflicts of interest regarding the publication of this paper.

\section{References}

[1] Steinberg, D.D. and Sciarini, N.V. (2006) An Introduction to Psycholinguistics. Pearson Longman, Harlow.

[2] Byram, M. (2004) Routledgeencyclopedia of Language Teaching and Learning. Routledge, London, New York, 82.

[3] Hornby, A.S. (2005) Oxford Advanced Learner's Dictionary of Current English. Oxford University Press, Oxford, 664.

[4] Latham, G.P. (2004) The Motivational Benefits of Goal-Setting. The Academy of Management Executive (1993-2005), 18, 126-129. http://www.jstor.org/stable/4166132 https://doi.org/10.5465/ame.2004.15268727

[5] Ballesteros Muñoz, L. and Tutistar Jojoa, S. (2014) How Setting Goals Enhances Learners' Self-Efficacy Beliefs in Listening Comprehension. HOW Journal, 21, 42-61. https://doi.org/10.19183/how.21.1.14

[6] Sujecka-Zając, J. (2016) A Competent Foreign Language Pupil. Mediation Challenges for Foreign Language Teachers. Wydawnictwo Werset, Lublin.

[7] Idowu, A., Chibuzoh, I. and I, M. (2014). Effects of Goal-Setting Skills on Students' Academic Performance in English Language in Enugu Nigeria. Journal of New Approaches in Educational Research, 3, 93-99. https://doi.org/10.7821/naer.3.2.93-99

[8] Moeller, A.J., Theiler, J.M. and Wu, C. (2012) Goal Setting and Student Achievement: A Longitudinal Study.

[9] Rubin, J. and McCoy, P. (2008) Lessons from Good Language Learners. Cambridge University Press, Cambridge, 294-305. https://doi.org/10.1017/CBO9780511497667.026 